\title{
10
}

\section{Central and eastern Europe}

\author{
PAUL G. LEWIS
}

The passage of over ten years since the first fully competitive elections should have succeeded in putting the progress of democratization in post-communist Europe into clear perspective. By now we might expect to have a reasonably firm comprehension of how far democratization has proceeded, why - if its achievements are differentiated - it has gone further in some countries than others, and which events and processes have driven democratic change. The looking-glass of democratization studies should in this sense have been ground sufficiently finely to develop a clear image of developments in the area and uncover their main dynamics. One might also expect some theoretical insight to have been distilled from the copious information that has already been garnered, if not the formulation of a fullyfledged theory of post-communist democratization. By and large, however, the prevalent view is that achievement in these areas has been limited. Although comparative politics was largely dominated throughout the 1990s by issues of democracy and the study of democratization, to date it has issued in extensive empirical accounts and rather disjointed conceptual discussion more than a comprehensive body of theory that contributes to a deeper understanding of democratization in general. How well the studies of central and eastern Europe (CEE) compare with other regions is debatable, but the perspectives developed so far tend to identify loose associations and broad problem areas rather than more precise relations of dependence and causality. The looking-glass in this sense offers rather a blurred image - although some part of this weakness may also lie in the eye of the observer. 
Taking $\mathrm{CEE}^{1}$ as a whole the progress of democratization can be outlined in basic terms fairly precisely. Competitive elections on a universal suffrage have been held, and their conduct and results broadly validated by international observers in the majority of the nineteen countries, although they have not proceeded without reservation in Russia, Ukraine and Albania (see Karatnycky 2001). Only Belarus is generally deemed to have remained authoritarian and generally unfree as a whole - it is one of the few countries to have seen such a steady decline in its freedom ratings that it has clearly moved out of the democratic, free category altogether. On this basis, employing Freedom House ratings in 2001, eleven states have clearly democratized successfully, while seven remain in the intermediate area of partial democracy. Virtually all have also passed Huntington's (1991: 266-7) 'two-turnover test', whereby not only do authoritarian rulers have to lose power for democracy to be installed, but so have their potentially democratic successors on at least one occasion too (Milošević's loss of power in the rump Yugoslavia being too recent for the test to apply there yet).

But in other respects the area of study remains little more than 'a conceptual mess': the issues of democratic transition and consolidation have been confused and the precise line between democracy and non-democracy not drawn with sufficient clarity (Kopecký and Mudde 2000). Bunce (2000a:) is somewhat less negative, identifying five broad conclusions about democratization and three further 'bounded generalizations', in the light of specific regional experience. Pacting between authoritarian elites and leaders of opposition forces was found to be more effective as a path to democratization in Latin America and southern Europe than it was in CEE, where a 'thoroughgoing political rejection of the Socialist past and Socialist elite' was found to provide a more solid basis for democratic governance. Whereas economic reform in the Third World is a hazardous project that could undermine democracy, the opposite was true in CEE, where the progress of reform and democratization were strongly interdependent. However, Bunce also concurs with Kopecký and Mudde about the conceptual and methodological weaknesses, and directs attention in particular to problems of concepts, case selection and causality. 
Kubicek's (2000) overview suggests that post-communist studies have so far contributed rather little to the field of comparative politics, and perhaps - with the exception of studies in political economy - may not generally be expected to do so in the future. The importance of social context for processes of 'transitology' (as democratization is termed here) is such that comparative study within the post-communist world is likely to be more fruitful than comparison across regions. Taken all together then, the substantial attention given to the CEE and abundant publications can only be seen as producing a disappointing outcome - but not one that differs greatly from democratization studies in other areas (Geddes 1999). Of course academic appraisals are rarely very approbatory anyway; moreover, the status of democracy in CEE (and, indeed, in regions with more established regimes) is itself still rather confused.

This chapter reviews how far democratization has progressed in CEE in concrete terms, discusses some major points of contention that have arisen, and identifies the main conclusions from the debate so far. It will show how democratization has been viewed in the CEE context and the nature of the conceptual lens (or lenses) that have been deployed to chart developments in this area. Little attention will be given to the early stages of democratization and the question of why the movement towards democracy began in the first place. Instead, the focus is on contemporary aspects of democratization and the most salient features of the regional pattern as it has developed over the past ten years.

\section{The progress of democratization}

An approximate guide to the level of democracy achieved in the region can be gained from the annual Survey of Freedom Country Scores compiled by Freedom House. The passage of time since the fall of the communist regimes gives us the opportunity to trace distinctive patterns of democratic development across the region. The country scores combine ratings for political liberties and civil freedoms that, if not an uncontentious index of democratic development, at 
least provide a reasonable guide. The scores have been criticized for being partial and too highly aggregated, but they do not diverge greatly from other prominent measures of democratic performance. Table 10.1 ranks CEE countries according to their Freedom Country Scores (FCS: low scores are more free) and, for those that share the same rating, by Gross Domestic Product (GDP) per capita. All 'free' countries on this basis count as 'electoral democracies', as do some of the 'partly free' countries (italicized figures) (Karatnycky 2001: 649). In 2000 Moldova, Macedonia, Yugoslavia, Albania, Ukraine and Russia all qualified as 'electoral democracies' in this category, but not Bosnia. The states with a score higher than 5.5 are categorized 'not free' (only Belarus in 2000) and are not defined as democratic.

Several features stand out. Eleven of the countries in CEE, rather more than half, were rated free in 2000 (scoring ratings of 2.5 or less), seven were partially free (from 3 to 5.5, the cut-off point between partially free and not free countries running through the 5.5 score), and just Belarus was rated not free. This was better than 1991, when only nine countries (more accurately, eight before the dissolution of the Czechoslovak republic) were judged free. All of those categorized as democratic in 1992, moreover, had maintained or improved on their score by 2000 - suggesting a general extension or deepening of the democratization process. This democratization tendency, however, did not exclude temporary backsliding in some cases. Slovakia was ranked as partly free for three years under Prime Minister Mečiar, when civil liberties were less fully observed. Estonia and Latvia also fell into this category soon after independence owing to problems in extending full democratic rights to the sizeable Russian minorities. Some observers defined the two Baltic states as authoritarian at the outset.

Of the eight partially free states in 1991, then, three had improved on their score by 2000 and five either stayed the same or regressed - three of these being the major post-Soviet republics of Russia, Ukraine and Belarus. The two countries rated not free in 1991-92 were the rump Yugoslavia and Bosnia, both involved in bitter conflict for 
the first half of the 1990s. The score of both improved when the hostilities ceased and the Milošević leadership in Yugoslavia was finally removed. Only Belarus remained on a resolutely 'unfree' course, as President Lukashenka consolidated his increasingly authoritarian rule. The picture overall, then, is of a certain progress in democratization through the decade accompanied, nevertheless, by a quite striking stability between the different groups of countries. Those already more democratically advanced in 1991 stayed that way and generally improved on their position. Those less favoured at the beginning of the decade often stayed at roughly the same level or actually regressed. Only Romania and Croatia moved out of the partially free into the free category. Belarus steadily moved towards the not free and fully authoritarian category. CEE developments seem to show a less uniform regional pattern of democratization than Latin America or southern Europe (Table 10.1).

However some significant associations at least can be identified, in addition to the failure of the major postSoviet republics to improve on their limited initial standing, as shown by the comparison with trends in Gross Domestic Product. The more democratic CEE states are both physically located to the west of the CEE region and closer to the West in political and economic terms as well. The four richest countries (Hungary, Poland, Slovenia and the Czech Republic) were amongst the five initially targeted for early accession by the European Union (EU) in 1997, while by 2000 ten of the eleven countries rated free were engaged in accession negotiations. Most were considerably wealthier than countries rated partly free or not free. Only one partly free country, Macedonia, was as rich as any of the 'free' countries - and it was wealthier than just two of the 'free' countries. The correlation of political and economic factors raises a number of questions about the origins and pattern of democratization, both in general and in the context of post-communist CEE. It points to the possible existence of common underlying factors shaping the process and relates directly to modernization theory one of the major paradigms claimed to provide an explanation for democratization. 


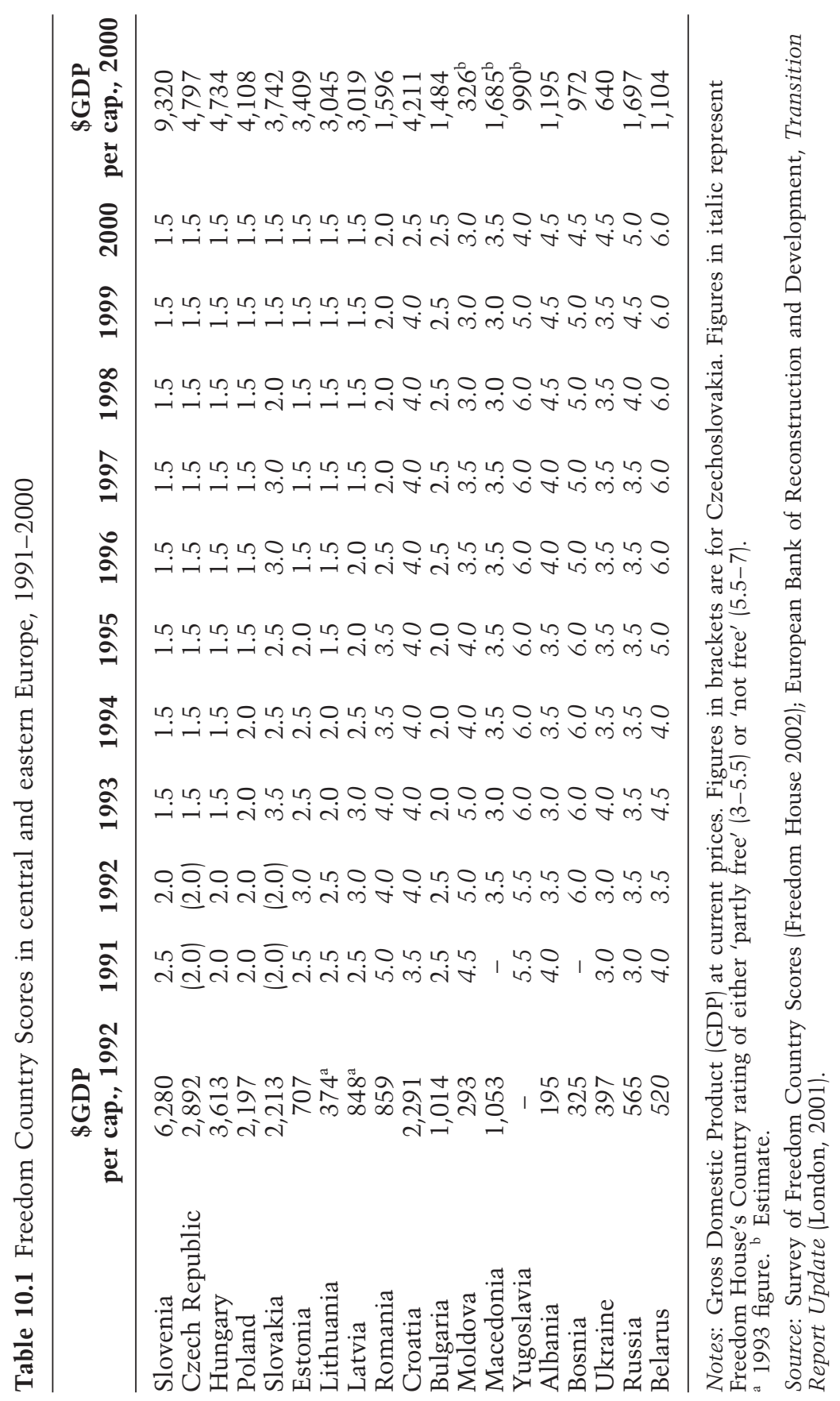




\section{Democratization and modernization}

The association of democracy with wealth in CEE during the early years of post-communism is hardly surprising in itself and echoes a well-known association between democracy and modernization that has been widely mooted since the 1950s. The precise nature of the association has, however, always been obscure, and there has been widespread doubt about whether modernization - generally understood to be based on economic growth and adequately reflected in GDP indices - actually explains much about democratization or democracy in any precise sense. Democratization in CEE has rekindled interest in this question; possibly, this recent experience sheds new light on a rather wellworn debate. Probably the most comprehensive statistical examination of the relationship concludes quite emphatically the 'emergence of democracy is not a by-product of economic development'. But it simultaneously endorses the obvious association of the two phenomena, affirming that 'while democracy is terribly fragile in poor countries, it is impregnable in the rich ones' (Przeworski and Limongi 1997: $166,177)$. In short, modernization cannot be understood to produce democracy, but once a reasonably wealthy country has become democratic it is likely to remain so.

These global findings are hardly exhaustive; indeed the relationship between modernization and democratization becomes more complex once historical and geographical differences are taken into account. Dictatorship in countries that became independent after 1950 was, for example, just as stable in rich as in poor countries (Przeworski and Limongi 1997: 176). ${ }^{2}$ Also, it is argued that a high level of economic development has had stronger democratizing effects in European countries than elsewhere, an observation that was particularly rooted in the relatively recent south European cases. Both internal and external factors were involved here, the latter primarily based on the powerful role of wealthy close trading partners and the strong political influence they exerted through the promise of EU membership. Economic development has been claimed to increase the chance of a peaceful evolution towards democracy. Political and economic outcomes have also been 
closely linked in studies of post-communist development. Economic reform seems to have promoted democratization in post-communist countries more consistently than elsewhere, and this may reflect some unique features of the CEE context (Fish 1998: 238). A careful analysis of the conditions for successful economic reform in the post-communist states traces its immediate roots to the character and outcome of the initial, 'founding' elections of 1990-91 that marked the political break with communism. The more thoroughgoing and clear-cut the break, the more likely that economic reform would be successful.

This, of course, does not tell us much about democratization itself, but some of the second-order effects of the main correlation exercise do bear more closely on issues of democratic change. Greater political openness, as shown by the data presented in Table 10.1, was closely correlated with the outcome of the initial elections and produced better conditions for economic reform, while macro-economic performance was also strongly reform-dependent. While hardly surprising, such linkages provide some basis for identifying a 'virtuous circle' of economic reform and democratic change in CEE, as well as directing attention to the conditions that give rise to a 'vicious' one like that in Belarus. Lukashenka's personal dominance and growing authoritarianism were based on the rejection of anything like price liberalization that might threaten short-term economic pain. This particular analysis is interesting, too, for having prompted further examination not just of the links between political and economic variables but also of the geographical differences within the CEE region that seem to reflect and amplify them. Why precisely should the more democratic CEE states be both wealthier and more western? A recalculation of Fish's data thus includes an extra variable for the average reform score of each state's contiguous neighbours, which turns out to be significantly correlated with the original economic reform measure. That is, the more western CEE countries were more effective reformers and probably wealthier - precisely because they were more western (Kopstein and Reilly 1999). In both an echo and advance on earlier disagreements about how far existing models of transition are able to 'travel' and furnish fruitful comparison, Bunce (2000b: 86) continued to stress the 
importance of regional characteristics - but with, nota bene, the proviso that 'it is precisely in the strategic realm - in needs, resources, possibilities, and outcomes - that regional context plays a powerful role in democratic transitions'.

The spatial diffusion of culture, power and economic variables may well, therefore, be an additional influence on the success of economic reform and the extent of democratization during this phase of the 'third wave'. Alongside a focus on political economy, democratization studies in CEE have placed considerable emphasis on the role of political culture and the nature of civil society. That is something that directs attention once more to the role in the European context of regional interconnectedness and the likelihood that, just as EU influence played a prominent role in south European democratization, so it would play an equivalent or even greater role in CEE developments. Thus 'modernization', for all its apparent links with democratization, may have little direct explanatory power in itself and offers limited value to theory-construction. But within a more closely defined historical and spatial context, its covariance with democratization indicators points to hitherto neglected ways in which regional factors and international influence can be factored into the analysis of democratic change. The implications of the analysis of CEE democratization and post-communist change more generally for the modernization perspective may thus be one part of the looking-glass where the view has indeed been sharpened and theoretically refined.

\section{Democratization concepts - transition, consolidation and stasis}

The concept of democratization as applied to central and eastern Europe has been unclear; moreover the subject has often been introduced as if the question of definition did not really arise: the process has become synonymous with a broader category of post-communist political change. This was signalled at the very outset, as the end of communist rule was unthinkingly (but almost universally) identified with initiation of the phase of democratic transition. Apart 
from its unhelpful teleological connotations, the 'transition' assumption embodied additional drawbacks in serving to smuggle in by these means a 'unifying and homogenizing effect vis-à-vis the multiple processes designated by the notion' (Dobry 2000: 5). There has generally been a failure to distinguish between the interlocking processes of democratic transition and consolidation; no stringent line between democratic and non-democratic regimes has been established; and the definition of democracy itself has not been properly separated from identification of the process or processes that produce it (Kopecký and Mudde 2000).

For example, transition can be understood to refer to a process of change that starts with the progressive collapse of an authoritarian regime, as the adoption of a new constitution, as routinization of new democratic structures, or as the adjustment by political elites of their behaviour according to liberal democratic norms. Consolidation on the other hand involves removal of the uncertainties that surround transition and the institutionalization of the new democracy, the internalization of its rules and procedures, and the dissemination of democratic values. The extensive remit of these definitions and the evident problems of operationalizing the different variables they denote aptly illustrate the problems involved and help explain why many analysts have fought shy of confronting them. Precisely when transition has ended and democracy is fully installed raises a number of questions for which clear answers are difficult to find: how routinized do democratic structures have to be, and which are the critical ones? Precisely which dimensions of their behaviour do political elites have to adjust, and which particular democratic norms are most important? How can we tell that lip-service to democratic principles does not mask the persistence of less acceptable patterns of behaviour that are not open to public scrutiny? A further layer of questions emerges at the consolidation phase that relate yet more closely to values and questions of subjective commitment, which are equally difficult to determine accurately.

In practice, making the distinction between democracies and non-democracies has not been such a challenge, at least in terms of identifying electoral or minimal democracies; and Freedom House data offer a reasonably convincing basis 
for drawing such a line. The fact that ten of the eleven countries identified as free in 2000 had been so for five or more years also suggests that their transition period had ended and they are now embarked on a subsequent phase of democratic development. Of the six partially free states classed as electoral democracies in 2000 just two had improved on the Freedom Scores assigned to them in 1991/2 (one being Yugoslavia shortly after Milošević). Far from being completed, transition in this group hardly seemed to be under way at all in most cases, and the process was largely stalled. Not all countries have been moving in a democratic direction, and the barrier between states that were free and democratic from the outset and those that have hovered in a partially free, semi-democratic state has barely shifted at all.

So, while transition and consolidation have been the main concepts around which the discussion of democratization has revolved, there is a further category - for countries that have moved only very slowly towards installing a reasonably convincing form of liberal democracy or, even, its most minimal electoral form. Kitschelt (2001) noted that postcommunist diversity as a whole emerged during a short period - from 1990 to 1993; since then, 'new regime structures have more or less "locked in" in almost all polities'. From this point of view, in CEE they were in fact more or less 'locked in' from the outset in 1991 and little change (in terms of broad free/non-free categories) was evident by 1994 . A fuller pattern for the second half of the decade was actually apparent in 1996, after which only the former warring countries of Yugoslavia and Croatia (Slovakia is a partial exception) changed categories.

There has been in this sense an underlying condition of stasis or arrested development that characterizes much of CEE democratization. This is yet one further aspect of political change - or the lack of it - that needs to be accounted for. To do so raises further major problems and directs attention to the underlying question of whether it is just the quality of the post-communist democracy itself that is partial and/or defective, or, instead, it is the concepts that are applied to characterize it that are faulty. This is not necessarily an issue that concerns all CEE countries equally; and as an issue for post-communist democratization 
it does not figure strongly in studies of the subject. Rather, much of the debate has moved on to issues of consolidation, although difficulties have been encountered even there in identifying what it means and how it might be empirically assessed - and in many cases the problem has just not been fully confronted at all. Both Bunce (2000a) and Kopecký and Mudde (2000) emphasize the critical failure to distinguish between the sustainability of democracy and its quality in any particular case.

One of the earliest major studies argued that democracies needed five 'interacting arenas' in place which had to be mutually reinforcing for consolidation to exist (Linz and Stepan 1996: 7). But whether the requirements in terms of civil society, the rule of law, a usable state bureaucracy, a relatively autonomous political society and an institutionalized economic society were prerequisites or elements of consolidation itself was not clear. Most analysts in fact direct their attention to aspects of political culture and lay great store on attitude surveys in providing evidence of consolidation. One of the most wide-ranging analytical studies concludes that the countries of east-central Europe (Hungary, Poland, Slovakia and the Czech Republic) have made considerable progress towards consolidation in the light of trend patterns that 'clearly indicate a rooting of democratic convictions' (Plasser et al. 1998: 188). These countries plus Slovenia, Bulgaria and Romania were also described as heading toward democratic consolidation 'albeit with some caveats and concerns', by Diamond (1999: 184$5)$, largely on the basis of attitude clusters that showed citizens endorsing the present regime over the previous one, rejecting authoritarian alternatives, and broadly favouring the activities of representative democrats. Other analysts are more sceptical. To return to the point from which this discussion began, then, the looking-glass through which CEE democratization is viewed does not just help shape the image that can be perceived but may also play a part in creating the political reality that it reflects. 


\section{Conclusions: Europeanization and the quality of post-communist democracy}

Different reasons have been identified to explain the deficiencies of the post-communist democracies. One dwells on the weak development of the rule of law and a consequent failure to build an adequate constitutional order (Merkel and Croissant 2000: 31-47). Another claims that basic institutions are absent: the new regimes have been installed in contexts that lack the framework of the modern state, the precondition of most 'first-wave' democracies and a necessary political basis that merits far greater attention. Thus, according to Rose and Shin (2001), many post-communist democracies (like others in the third wave) have 'started democratization backwards'; thereby failing to go much beyond 'electoral democracy'. The view that institutions often determine, rather than are determined by, the events of history is supported by a wide-ranging survey of CEE democratization processes: 'It is remarkable how the choice of this or that institution... makes an important change in the way that otherwise similar societies can develop at a point of major transformation' (Sadurski 2001: 455). What is not always appreciated is that many post-communist states face not just the double transition of political and economic transformation, nor even a triple change that adds state formation, but a yet more complex challenge of quadruple transition involving distinct processes of nationbuilding and state construction.

It is, therefore, increasingly realized that the process of post-communist democratization (though perhaps not that much less than any other) is a multifaceted and highly complex one, where several critical factors are highly interdependent. Constitutionalism is thus of great importance for the development of post-communist democracy, not just because of its association with the development of a Rechtsstaat, accountable democratic processes and a legal basis for the conduct of democratic politics, but also because of the less directly instrumental functions it performs in literally serving to constitute the body politic and form an inclusive political identity (Sadurski 2001: 462-3). This dimension is not far removed from the much discussed 
(but often loosely defined) issues of political culture that are thought to be central to the process of post-communist democratization. The character of this democratic culture is often associated with the beliefs and practices already well established in western Europe. Democratic development is often identified with Europeanization in this sense - the assumption of a consciously (west) European identity - and is in practice intimately associated with both structures and processes that are designed to lead to formal EU membership. A major problem here is that any contemporary European identity is remarkably difficult to define. The supra-national principles promoted by the EU's founders have lost much of their meaning and force, after a half-century of peace and material wealth. 'Europe' has come to represent values that are largely instrumental and has lost the capacity to strengthen or provide the democratic culture and democratic identity needed by the postcommunist countries. The close link between material wealth and democratic achievement thus confirms a selfreinforcing dynamic of European integration and general westernization, but also a view of politics that is essentially technocratic.

The democratic deficit much deplored in EU institutions and processes is thus also reflected in the ambiguities of CEE democratization and the sharp division drawn between the more wealthy democratic countries close to EU membership and the second (or third) division of those slower or even stalled in the democratization process. Democratization has not always been advanced nor the cause of democracy necessarily well served by the strengthening of west European links. The top-down approaches often adopted have not been particularly effective in strengthening processes of democratic consolidation or tackling the weaknesses of civil society so often identified as major limitations. Democratic conditionality has been a blunt instrument that is disproportionately harsh on the states slowest to embark on economic and political development. Zielonka (2001) confirms that CEE democracy has been to a significant extent 'foreign made' and that democratization has been externally facilitated and supported from outside. The major question that concerns us in this context, though, is how far the actual image of democratization has also been affected by the 
Western looking-glass and the interpretation of political practice in contemporary CEE perhaps distorted by requirements of conditionality or the demands of EU accession procedures. International pressures more generally have imposed strict restraints on the exercise of self-rule by CEE 'democratic' government.

Globalization clearly limits the sovereignty of the region's new democracies. It encourages unpopular policies and prompts governments to renege on election campaign promises, presses (sometimes forces) leaders to act against the preferences of the electorate, restructures the political space in ways likely to endanger democratic stability, and promotes state reorganization on more repressive lines (Zielonka 2001: 519-20). These mark out major areas of conflict between the dominant conceptions of economic and political change. Processes of democratization and capitalist development are closely linked - after all, modernization theory implies that political and economic change are in some way part of the same package. And close analysis of post-communist change indeed suggests that the economic components of the package take precedence over the political. Yet stronger arguments can also be made that the political effects of economic liberalization and market growth are often identified with democratization even though there is little empirical or theoretical support for such a conclusion.

It is the latter view that would support the case for the looking-glass of democratization studies creating its own image of post-communist political processes distinct from a more 'objective' reality. There are certainly some grounds for coming to such a conclusion, given that the idea of democracy has been stretched globally to cover a wide variety of politically unresponsive and relatively unaccountable regimes where the quality of democracy also often appears to be remarkably thin. Analysis of CEE democratization processes is also, as we have seen, highly inconclusive in the light of widespread conceptual confusion and failure to distinguish between different levels of analysis. What is more clear is that those countries that are attractive candidates for European integration and have the resources needed to participate in the process are regarded as more viable partners and acceptable democratic models 
of post-communist development. If the criteria for democratization themselves remain vague, there is, paradoxically, far more stability and clarity about which of the CEE states are deemed to meet them.

\section{Notes}

1 Nineteen post-communist states including Russia (also a major Asian power), but excluding the transcaucasian states and the former Soviet territories in Asia.

2 Przeworski and Limongi (1997) nevertheless restore some explanatory power to modernization by suggesting that socio-economic development at least worked in the right direction in long-standing dictatorships like those in CEE that did eventually fall. However, much of this can be attributed to the removal of the Soviet veto; and it was precisely in Poland, the leader and major catalyst of CEE democratization, that GDP began to fall in 1979 and did not regain its former level until the 1990s. 